\title{
㩆 \\ Los editores independientes y la constitución
de un capital simbólico transnacional:
condiciones sociales del ingreso de la
diversidad cultural en Chile
} RMA

\author{
Mauricio Bustamante Fajardo* y Constanza Symmes Coll**
}

Antropología Social

*École des hautes études en sciences sociales (EHESS). Centre européen de sociologie et de science politique (CESSP), París, Francia. Email:

m.bustamante@ehess.fr .**École des hautes études en sciences sociales (EHESS). Centre européen de sociologie et de science politique (CESSP), París,

Francia. Email: conysymmes@gmail.com

\begin{abstract}
Resumen
Bajo el prisma de la circulación internacional de ideas, este artículo presenta un análisis sobre las condiciones sociales que trazaron el itinerario transnacional del principio de diversidad cultural entre agentes y estructuras de distinto orden (organismos internacionales, Estados y asociaciones de profesionales de la cultura). Este principio acumula en su trayecto un capital simbólico, tomado y reinvertido por un sector del mundo cultural chileno para la rehabilitación de la cultura como una categoría de intervención pública. Acogida y traducida a la escena nacional, la causa de la diversidad cultural responde a dinámicas que no pueden ser entendidas, sino a la luz de una homología estructural de posiciones entre agentes diferentes, situados a distintas escalas. En el plano internacional las ideas no circulan por sí solas, se estructuran dentro de un espacio de posibilidades a nivel nacional. Desde esta perspectiva, se mostrará de qué manera la movilización de los editores independiente fue determinante en la inscripción de la diversidad cultural en Chile.
\end{abstract}

Palabras clave: diversidad cultural, capital simbólico transnacional, edición independiente, circulación internacional de ideas, políticas culturales.

Independent publishers and the building-upof a transnational symbolic capital: social conditions for the emergence of cultural diversity in Chile

\begin{abstract}
From the perspective of the international circulation of ideas, this article presents an analysis of the social conditions that made possible the transnational circulation of the concept of cultural diversity among different agents and structures (international entities, National States and professional cultural associations). Through this circulation, the concept has accumulated a symbolic capital, which has been taken up and reinvested by some sections of Chile's cultural world in order to rehabilitate culture as a category of public intervention. Translated into Chile's reality, the cause of cultural diversity responds to dynamics that can only be understood considering a structural homology of positions between varieties of agents situated at different levels. At an international level, ideas do not circulate independently; they are structured within a space of possibilities that exist at a national level. From this view, we will show how the mobilization of independent publishers was a determining factor in the adoption of the principle of cultural diversity in Chile.
\end{abstract}

Key words: cultural diversity; transnational symbolic capital; independent publishing; international circulation of ideas; cultural policies.

\begin{abstract}
"La ciencia social debe englobar en la teoría del mundo social una teoría del efecto teórico que, contribuyendo a imponer una manera más o menos autorizada de ver el mundo social, contribuye a hacer la realidad de ese mundo" (Bourdieu 1999: 66).
\end{abstract}

En el presente artículo proponemos un estudio sobre la circulación internacional de ideas y sus apropiaciones locales, analizando particularmente sus efectos en el ámbito de la cultura. Abordaremos en un primer momento, los debates internacionales que llevaron a ciertas organizaciones intergubernamentales a pronunciarse sobre el concepto de diversidad cultural y que condujeron -en el año 2005- a la adopción en la Unesco de la ya muy citada Convención sobre la 
protección y la promoción de la diversidad de las expresiones culturales (en adelante Convención sobre la diversidad cultural). Enseguida y centrando nuestro análisis en el proceso histórico y social de irrupción del concepto de diversidad cultural, ofreceremos elementos para comprender el contexto de gestación y circulación de ideas (Bourdieu 2002) entre organismos internacionales, gobiernos y actores no estatales.

Sin pretender exhaustividad, nos interesa radiografiar la trayectoria específica que delineó el ideario de la diversidad cultural en diversas asociaciones profesionales de la cultura de múltiples países, lo cual dio origen a la articulación de una acción colectiva que puede ser observada a la luz de una contestación transnacional (Tarrow 2000). ${ }^{1}$ Como lo afirma Abram de Swaan, la sociología de la sociedad transnacional tiene como tarea primordial estudiar las relaciones "que unen personas más allá de las fronteras, directamente o a través de los gobiernos, las empresas transnacionales y otras organizaciones. Esta es la razón por la cual la sociología debe esforzarse menos por dar cuenta de las relaciones existentes entre los Estados que de la relación entre los ciudadanos de los diferentes países y, por lo tanto, acerca del papel de los Estados, las empresas y las instituciones internacionales en el establecimiento de estas relaciones"(De Swaan 1998). Desde esta perspectiva pasaremos a examinar cómo y bajo qué condiciones ciertos conceptos producidos, legitimados y visibilizados por organismos internacionales, son recogidos, adoptados y movilizados por una parte del mundo cultural chileno, en particular por el sector de la edición independiente.

En su mayor parte creadas en los años 1990, estas editoriales - pequeñas y medianas - se definen fundamentalmente bajo la categoría de "independientes" para diferenciarse de aquellos de perfil "concentrado" encarnado por los grandes grupos de la edición, los cuales se han ido conformando como resultado de operaciones de adquisición-fusión de gran magnitud en el mercado del libro. Dentro del amplio panorama de asociaciones profesionales de la cultura existentes en Chile, los editores independientes presentan ciertas características específicas que han despertado nuestro interés. ${ }^{2}$ En primer lugar, señalaremos el desarrollo de una

\footnotetext{
1Este término proviene del inglés "transnational contention" (Tilly et al. 2001), que en francés se ha venido traduciendo como "contertation transnational" (Tarrow 2000). Somos conscientes que la traducción empleada frecuentemente en español es "acción colectiva transnacional". Sin embargo, creemos que la palabra contestación dilucida mejor la idea que trataremos de exponer más adelante, término que la Real Academia Española define de la manera siguiente: "polémica, oposición o protesta, a veces violenta, contra lo establecido". Recogemos en consecuencia la idea de contestación transnacional como una figura explicativa de la articulación de reivindicaciones -en un momento determinado y bajo condiciones sociales concretas- de una red de organizaciones no estatales en varios países.

2 Este artículo moviliza materiales empíricos producidos a partir de dos investigaciones, en el marco de la realización de nuestras tesis doctorales. Estos consisten en un conjunto de aproximadamente 80 entre-
}

capacidad organizativa de trabajo en redes, a diferentes escalas, que va desde lo regional a lo local, y desde ahí a lo supranacional; y en segundo lugar, sus modos de incursión en el espacio público, caracterizados por una suerte de militancia cultural, que lo ha dotado de un importante capital simbólico. Dicho capital se reforzó de manera contundente con la internacionalización de su accionar, revelándose como una estrategia de supervivencia dentro del campo cultural nacional.

Este conjunto de propiedades y experiencias serán determinantes para su integración en el proceso de circulación internacional del principio de diversidad cultural, en el cual van a jugar un rol preponderante como estructuradores del mundo cultural al seno de la Coalición chilena por la diversidad cultural. Los editores independientes chilenos se posicionan de manera local reivindicando, frente a los responsables de las instituciones encargadas del sector de la cultura de su país, la necesidad de contar con políticas públicas que resguarden la producción cultural nacional. En consecuencia, nos interesa comprender cuáles han sido los agentes que participaron en este proceso, sus formas de apropiación de un discurso internacional y las estrategias de instalación local del debate, en un momento en el que el gobierno chileno se preparaba para firmar un Tratado de libre comercio (en adelante TLC) con EEUU. Es necesario mencionar que este proceso se desarrolla en un país cuyo contexto sociopolítico y cultural está marcado por la transición hacia la democracia. Aunque no vamos a entrar aquí en un debate sobre la denominada "transitología" (Joignant 2009) consideramos indispensable señalar que la transición instala a los agentes en un escenario político, social y cultural particular, configurado por las propias lógicas que subyacen a este proceso y que están determinadas por la existencia de ciertos "enclaves autoritarios" (Garretón1995) y por la continuidad, en los tiempos democráticos, de un modelo económico neoliberal instalado bajo el régimen militar. El espacio cultural constituye sin duda un elemento revelador del tipo de transición que ha tenido Chile, de sus tensiones y posibilidades.

\section{La diversidad cultural en la UNESCO: genealogía de un debate}

En el plano internacional, a partir de la segunda mitad del siglo XX, la cuestión cultural ha sido objeto de constantes controversias (Gagné 2005), en particular porque se encuentra entre dos concepciones completamente opuestas en lo que concierne el tratamiento de los productos culturales. La primera, consiste en pensar los productos culturales a partir del principio según el cual "el mercado garantiza la mejor asignación de recursos",

vistas en profundidad, algunas de las cuales fueron realizadas conjuntamente por ambos investigadores; de datos cuantitativos sobre la edición en Chile; de análisis bibliográfico de libros publicados por los editores independientes en Chile; y de un trabajo sobre los archivos de la Unesco en sus sedes en París (Plaza de Fontenoy y Rue Bonvin). 
asegurando una mejor diversidad de productos; la segunda considera, por el contrario, que "la cultura no es una mercancía como las otras", y debe beneficiarse de un tratamiento específico (Mattelart T. 2011). Conforme a esta última, el principio de diversidad cultural se enraíza en el seno de la Unesco sobre una prerrogativa: el rol de las políticas públicas en favor de la cultura, es decir en el papel que juega el Estado y sus instituciones como mediadores culturales.

Los debates internacionales en torno a la importancia de las políticas públicas en los intercambios culturales aparecen en la Unesco a comienzos de los años 70 y se cristalizan en la década siguiente. Varias conferencias se llevaron a cabo en cada región del planeta ${ }^{3}$, en las cuales se va forjando un concepto de cultura que va "más allá de las bellas artes y el patrimonio", hasta llegar a integrar las visiones del mundo, los sistemas de valores y creencias. Sin embargo, la conferencia organizada en Ciudad de México en 1982, cierra esta secuencia de reuniones regionales y amplía la concepción misma de la cultura, afirmando que debe ser considerada como "el conjunto de los rasgos distintivos, espirituales y materiales, intelectuales y afectivos que caracterizan a una sociedad o a un grupo social. Ella engloba, además de las artes y las letras, los modos de vida, los derechos fundamentales al ser humano, los sistemas de valores, las tradiciones y las creencias"4.

En este periodo, la Unesco se convierte asimismo en ágora de debates mucho más espinosos, que apuntaban principalmente al desequilibrio entre la circulación de información entre los países industrializados y aquellos en vía de desarrollo. La década de 1970, en efecto, estuvo marcada por las peticiones del llamado "Tercer mundo" para un reequilibrio del flujo de intercambios culturales, dirigidas principalmente a las grandes agencias de noticias occidentales. En 1976 se constituye la Comisión Internacional para el Estudio de los Problemas de la Comunicación ${ }^{5}$, con el propósito de crear un Nuevo orden mundial de la información y la comunicación (NOMIC), contribuyendo a dar una gran visibilidad al problema de los flujos de los intercambios (Mac Bride 1988).

Estas iniciativas de transformación fueron promovidas por el Movimiento de Países No Alineados (MPNA). De hecho, la llegada de los Estados recientemente descolonizados

\footnotetext{
3 Entre otras: la Conferencia Intergubernamental sobre Políticas Culturales en Europa (Finlandia, 1972); en Asia (Indonesia, 1973); en África, (Ghana, 1975), en América Latina y el Caribe (Bogotá, 1978).

${ }^{4}$ UNESCO. 1982. Conferencia Mundial sobre las Políticas Culturales (Mondiacult). México, Informe Final, p. 42. Este concepto de cultura se incluirá en la Declaración Universal de la UNESCO sobre la Diversidad Cultural, en 2001.

${ }^{5}$ Esta Comisión estaba integrada por personalidades de renombre internacional como Gabriel García Márquez, Hubert Beuve-Méry, Marshall McLuhan, entre otros y presidida por Sean Mac Bride, fundador de Amnistía Internacional, Premio Nobel de la Paz en 1974 y Premio Lenin en 1977.
}

a los organismos internacionales, incluidas las Naciones Unidas, hizo tambalear el equilibrio y las alianzas establecidas. ${ }^{6}$ La justificación de la intervención de los poderes públicos en el sector cultural se formalizó a través de una concepción universalista de acceso a la cultura, esta última desde una visión democratizadora de las obras artísticas. La presencia sustancial del "desarrollo" como paradigma de la época sella también la legitimidad de la participación del Estado en el sector cultural: "la idea de desarrollo se ha ampliado, diversificando y profundizando gradualmente y el de desarrollo cultural se concibe ahora como parte integrante del desarrollo global que, como tal, debe ser objeto de una política de dimensión nacional"7.

Las principales objeciones de los "países occidentales"8 se ubicaron en la línea que, regular la circulación de la información y productos culturales, conduciría a una forma de manipulación anunciada por parte de los regímenes autoritarios. Ciertos países europeos y EEUU, que estaban en posición dominante, se sentían privados de una parte del mercado así como -enplena Guerra fríaveían en las políticas públicas la pérdida de un medio de influir los países del Sur (Mattelart A. 2005). La tesis de la "circulación equilibrada" de los países del sur del hemisferio, se deslegitimará poco a poco en beneficio del principio de "libre circulación", tesis completamente opuesta.

La Unesco, por su parte, será acusada de no tener en cuenta sus competencias institucionales en sus observaciones, y perderá la autoridad para discutir sobre la materia ${ }^{9}$. De hecho, las controversias en torno a las iniciativas para enmarcar internacionalmente ciertos debates sobre los intercambios culturales, debilitarán el alcance de los trabajos de este organismo durante varios años, sobre todo en cuanto se refiere al tratamiento de la cultura y las políticas públicas en su favor. EEUU abandona la Unesco en 1984, seguido del Reino Unido al año siguiente, esperando una reacción en cadena que desestabilice la organización. Estos países no tardan en

\footnotetext{
6 La región "África", por ejemplo, pasó de contar con tres Estados presentes en la Unesco a finales de los años 50, a cerca de 30, diez años más tarde, y cerca de cuarenta a finales de los años 70. En el mismo período Europa poseía 30, lo que causó muchas polémicas en la organización (Goy 1974).

7UNESCO. 1970. Conferencia Intergubernamental sobre los Aspectos Institucionales, Administrativos y Financieros de las Políticas Culturales, Venecia, Informe final, p.7.

8 Encabezados principalmente por EEUU y el Reino Unido. Este término fue comúnmente utilizado tanto por los funcionarios de la Unesco como por la prensa de la época para designar los tres bloques de mayor influencia presentes en la organización: "los países del Este", "los países No-alineados" y "los países occidentales".

9 Por ejemplo, la Comisión Nacional Francesa para la UNESCO, en un comunicado en 1979, con "un espíritu constructivo" recriminaba a la Comisión Mac Bride de "no tener en cuenta la competencia específica de la UNESCO y la necesidad de expresar una clara distinción entre lo que compete a la UNESCO y lo que es la responsabilidad de otras organizaciones internacionales". Archivos de la Unesco, CIC/30, "Press cuttings 1979-1981"
} 
realojarse en otras instituciones internacionales, en donde van a instaurar la "libre circulación" mediante acuerdos de liberalización de los productos culturales, en particular, en las negociaciones de orden económico ${ }^{10}$.

\section{La excepción cultural y la emergencia de una acción colectiva del mundo de la cultura}

"La cultura no es una mercancía como las demás" fue el lema ampliamente consensuado entre los responsables públicos franceses, desde que Jack Lang acuñase el término excepción cultural en los años 80. Políticos franceses, de derecha como de izquierda, han empleado este argumento para resaltar la importancia de esta excepción frente a la mercantilización de los productos culturales. Es precisamente por esta razón que la excepción cultural fue identificada como la "excepción francesa", aludiendo a la tradición en que se encuentra arraigada en el campo político galo, desde el establecimiento de la cultura como categoría de intervención pública (Dubois 1999). La excepción cultural se exaltó como respuesta a las negociaciones de carácter comercial, especialmente sobre el sector audiovisual, que habían comenzado a finales de los 80. Francia y Canadá estuvieron desde el comienzo en la base de esta reflexión, pero con lógicas un poco diferentes. Para los franceses la principal preocupación era mantener la calidad de la producción, mientras que para Canadá, equilibrar el intercambio de productos culturales con sus vecinos, en particular con EEUU. ${ }^{11}$

El marco en el que por primera vez se discute el principio de excepción cultural en una negociación comercial multilateral, fue la Ronda de Uruguay (1986-1993). En este ciclo de negociaciones, la Comunidad Económica Europea (CEE) se muestra muy abierta a incorporarla a la mayoría de los servicios, pero reivindicando al mismo tiempo una cláusula de no negociabilidad de los sectores audiovisual, cultura, salud y educación. De hecho, es gracias a la movilización del mundo artístico, sobre todo francés y belga, que se remecieron las negociaciones obligando, en parte, bajo la presión de los poderes públicos franceses y belgas, a reconsiderar la posición de la CEE.

\footnotetext{
10 Si la liberalización del comercio a nivel internacional se inició con la firma del GATT en 1947, ésta mantuvo un alcance relativamente limitada durante muchos años en cuanto respecta a los productos culturales, por varias razones. En primer lugar, un reducido número de países firmaron los acuerdos, hasta que llegara la Ronda de Tokio en 1979 y sus 102 signatarios. En segundo lugar, el GATT apuntaba al intercambio de bienes, excluyendo los servicios de los ciclos de negociaciones. Finalmente, el GATT no trabajaba de manera continua hacia el librecambismo, era un proceso que se activaba en cada ciclo de negociación, y de acuerdo a los resultados precedentes.

11 Existe una dependencia por parte de Canadá hacia los productos culturales de base de los EEUU, que aumentó de 31,5\% al 40,2\% entre 1994 y 2003 . México resultó ser el cuarto destino de las exportaciones de EEUU en 2003, gracias al Acuerdo de Libre Comercio de Norteamérica (TLCAN), que ofrece acceso preferencial a los productos de EEUU en el mercado de ambos países (Unesco 2005: 29).
}

"Organizamos un tren al Parlamento europeo en Estrasburgo, con Jack Ralite, que era un poco el motor, pero con muchos otros a la vez. Incluso hubo gente como Catherine Deneuve, Gerard Depardieu, grandes rostros protagónicos entre los artistas, directores como Bertrand Tavernier, etc. Había muchas estrellas en 1993, nos habíamos movilizado de tal manera para hacer ver la situación que el negociador europeo, León Brittan, que era un inglés ultra-liberal, se vio obligado a tomar en cuenta la posición del mundo profesional y la posición del mundo político, que estaba liderada por Francia, pero también por los belgas, creo que no habían otros. León Brittan se vio obligado a negociar con el delegado de EEUU, algo que para entonces llamamos excepción cultural, que era muy poco conocido y mal comprendido." (Entrevista con Claude Michel) $^{12}$

Dos cláusulas fueron concretamente la causa de la irritación de los profesionales de la cultura en las negociaciones de la Ronda de Uruguay: la cláusula del Tratamiento nacional (TN) y la cláusula de Tratamiento de nación más favorecida (TNMF). La primera consiste en acordar a las empresas extranjeras el mismo tratamiento que a las nacionales. Sin embargo, en Francia los profesionales de la cultura veían en esta cláusula una amenaza para la política cultural francesa en su conjunto:

\begin{abstract}
"Por supuesto, es terrible, el productor de Hollywood no necesita el fondo de apoyo del cine francés. Tienen tanto capital allá, que beneficiarse de nuestra ayuda es como demoler el fondo de apoyo del cine en Francia. No es justo. Estas exenciones a la regla del tratamiento nacional dieron la posibilidad de mantener el Fondo de apoyo al cine." (Entrevista con Claude Michel)
\end{abstract}

La segunda cláusula (TNMF) consiste en que el Estado acuerde a todos sus pares, las mismas condiciones que concede a los más favorecidos de ellos, lo cual se traduce en la eliminación de todo tipo de acuerdos de coproducción y de distribución con los países del sur, quienes tienen una producción cinematografía menos desarrollada y/o pocos recursos para su financiamiento. Situación a menudo de muchos países africanos y latinoamericanos, que se han beneficiado del Fonds Sud Cinema (FSC), creado por Francia en 1984. Contra la voluntad de los librecambistas, las demandas de los profesionales de la cultura tuvieron gran éxito. Al final de las negociaciones, en otoño de 1993, la Comunidad Europea se mantuvo muy abierta en la mayoría de los servicios, pero no tomó ningún compromiso de liberalización en los sectores audiovisual, de la cultura, la salud y la educación.

\footnotetext{
${ }^{12}$ Entrevista con Claude Michel, Miembro de la directiva de la Coalición francesa por la Diversidad Cultural. París, 26 julio de 2011.
} 
"Lo que obtuvimos en el 93 es un gran altercado. Y estas exenciones, lo que llamábamos excepción cultural, era: 'no se debe tratar la cultura como una mercancía como las demás porque no lo es'. Lo que es una gran idea. Hagan librecambismo con los coches, con el banco, con todo lo que quieran, incluso hasta con algunos servicios, pero no con la cultura. De hecho, casi de inmediato nos planteamos que tampoco debería hacerse ni con la educación, ni la salud, porque si todo es mercancía, si el mundo se convierte en una mercancía, ¿qué es lo que nos queda? Esto es desde luego un gran peligro para el equilibrio del ser humano" (Entrevista con Claude Michel).

Sin embargo, en 1998 la historia se repite. Esta vez, las negociaciones fueron emprendidas por la Organización para la Cooperación y el Desarrollo Económico (OCDE) en el marco del Acuerdo Multilateral sobre la Inversión (AMI), que podríamos considerar como la última gran batalla de la excepción cultural. Las razones que llevaron al fracaso del AMI son numerosas, pero el tratamiento que se dio a la cultura fue sin duda un factor decisivo. El proyecto del acuerdo tenía como objetivo dar a los inversionistas extranjeros los mismos derechos que los inversores nacionales, es en realidad un proyecto mucho más estricto que aquello discutido en la Ronda de Uruguay, es decir, los inversionistas privados extranjeros tienen la posibilidad de acudir a un tribunal de arbitraje, cada vez que sientan que sus intereses (económicos) se vean perjudicados. El proyecto del AMI era una clara iniciativa de desmantelamiento de las modalidades nacionales de regulación pública. Cabe mencionar, por ejemplo, que se apostaba a la libre circulación de servicios, lo cual incluía la exportación, importación, distribución de películas y otras grabaciones para salas de cine o televisión (Baer 2003).

En este escenario los sindicatos franceses, fundamentalmente del sector audiovisual, comienzan a agruparse y movilizarse, alertados por las negociaciones internacionales que alcanzaban a la cultura. Pero esta vez, irían más lejos, creando un Comité de vigilancia "para estar alerta contra la ofensiva estadounidense en el campo de la cultura, [...] y preservar la excepción cultural". Comité que años más tarde se convertiría en Coalición francesa por la diversidad cultural.

"Eso sobrepasaba la cultura, incluía todas las inversiones inmateriales, incluía todos los sectores, salud, educación, social y por supuesto también la cultura. Entonces, el análisis que hicimos en ese momento, era que el AMI sería muy devastador, que era mucho peor que la Ronda de Uruguay, que se centraba en los servicios audiovisuales y cinematográficos. El AMI encerraba todos los servicios de inversión, todo lo que se podía etiquetar como inversión.
Los Estados Unidos sabían lo que estaban haciendo. Empujaban, empujaban, y empujaban esta negociación, lo que no pudieron obtener en la Ronda de Uruguay, la querían obtener con el AMI [...] Lo que no pudieron hacer entrar por la puerta querían meterlo por la ventana" (Entrevista con Claude Michel).

Como se puede observar, el Comité de vigilancia va más allá de una simple acción colectiva de protesta, se constituye como un movimiento social (Neveu 2000). Este último concebido como una interacción prolongada entre las personas detentoras del poder y aquellas que no lo detentan (Tilly et al. 1998). Los participantes implicados en este movimiento hacen sus reivindicaciones ante las autoridades, al mismo tiempo que afirman una forma de identidad colectiva, basada en sus recorridos como agrupaciones de profesionales de la cultura, mostrando que son actores pertenecientes a un grupo solidario y de gran alcance. Con gran eficacia, estos grupos dan visibilidad a sus reivindicaciones, contribuyendo a construir una identidad que les permita compensar la falta de recursos políticos para promover sus demandas (Tilly et al. 1998).

Las movilizaciones colectivas de manera general y las acciones emprendidas en el seno de un movimiento se estructuran en función de repertorios de acciones colectivas alternativas, constituidas históricamente (Tilly 1978; McAdam 1983). Sin embargo, a diferencia de otros movimientos sociales, aquellos promovidos por los profesionales de la cultura poseen características particulares. Por ejemplo, las acciones que emprenden para que sus reivindicaciones sean atendidas por los poderes públicos, no buscan necesariamente la movilización ciudadana masiva. Conformada por personalidades del mundo artístico, los "rostros protagónicos" dan una gran visibilidad a sus reivindicaciones en el espacio público y los convierte en actores particularmente privilegiados ante los oídos del poder político. El capital simbólico de sus miembros se transforma en una verdadera herramienta de presión política.

Pensar el relativo éxito de la movilización de estos profesionales a partir de sus recursos simbólicos específicos, implica necesariamente esbozar el concepto de capital simbólico. Según Bourdieu "toda especie de capital (económico, cultural, social) tiende (en diferentes grados) a funcionar como capital simbólico (de modo que tal vez valdría más hablar, en todo rigor, de efectos simbólicos del capital) cuando obtiene un reconocimiento explícito o práctico, el de un habitus estructurado según las mismas estructuras del espacio en que se ha engendrado"(Bourdieu 1997: 285). Es decir, el capital simbólico (el honor, la honorabilidad, el prestigio, la reputación) es aquello en lo que se convierte cualquier especie de capital cuando es desconocido como tal; es decir, en tanto que fuerza, poder (actual o potencial) y, 
por consiguiente, reconocido como legítimo o marcado con cierta legitimidad. Para Bourdieu, el capital simbólico, "fruto de la transfiguración de una relación de fuerza en relación de sentido", es la posesión de una forma de conocimiento y reconocimiento de los otros, pero también la detentación del "poder de reconocer, de consagrar, de hablar con éxito, de lo que merece ser conocido y reconocido, y, más generalmente, decir lo que es, o mejor aún, en qué consiste lo que es, qué hay que pensar, mediante una manera performativa de decir (o de predecir)" (Bourdieu 1997: 285).

Los efectos de las acciones emprendidas por los profesionales del campo cultural, así como del capital simbólico de los movilizados, no tardan en llegar. En octubre de 1998, el Primer Ministro Lionel Jospin ${ }^{13}$ anunció la retirada de Francia para pedir la reanudación de las negociaciones en la OMC, que le parecía ser una instancia más democrática por el mayor número de países participantes. Pero, su posición era relativamente marginal entre los países europeos, al ser percibida como una medida proteccionista. Sin embargo, estos hechos revelan la viabilidad de excluir a la cultura de los acuerdos comerciales internacionales, aunque con resultados hasta ese momento poco decisivos. El accionar de los grupos de profesionales de la cultura fue igualmente crucial para impulsar la máquina de la excepción y a su vez presionar a sus gobiernos limitando el alcance de estos acuerdos. Sin embargo, la instauración de la Organización Mundial del Comercio (OMC) y sus mecanismos de liberalización de mercado vienen a limitar con creces el alcance de la excepción cultural. ${ }^{14}$

En este contexto, la Unesco organiza junto a la ONU el Decenio Mundial del Desarrollo Cultural (1988-1997) y se constituye la Comisión Mundial de la Cultura y del Desarrollo, presidida por Javier Pérez de Cuéllar, antiguo secretario general de la ONU (1982-1991), quien presenta un informe final (Pérez de Cuéllar 1997) en la Conferencia Intergubernamental sobre Políticas Culturales para el Desarrollo, celebrada en Estocolmo en 1998. Esta última concluye con un "plan de acción", en el cual, el tema de la diversidad cultural era presentado

\footnotetext{
13 Lionel Jospin (1937) fue Primer Ministro de Francia entre 1997 y 2002. Ex estudiante de Sciences-Po y de la prestigiosa École nationale d'administration, ENA, ingresó al Partido Socialista (PS) en 1971. Especialista en economía, se desempeñó como primer secretario del Partido Socialista durante los primeros años de gobierno de François Mitterrand (1981-1988). Fue ministro en varias ocasiones, en el gobierno de Michel Rocard, Cresson Edith y Beregovoy Pierre. Elegido candidato socialista en las elecciones presidenciales de 1995, fue derrotado en la segunda vuelta por Jacques Chirac y para entonces se pone a la cabeza del PS en octubre del mismo año. Posteriormente fue candidato en la elecciones presidenciales del 2002, pero no logra pasar a la segunda vuelta, eliminado por el inédito ascenso del candidato del partido "Front Nationale", representante de la ultraderecha francesa. Este evento marca la retirada de la vida política de Jospin.

${ }^{14}$ Creada en 1994, la OMC es una institución que opera fuera de las rondas y dispone de una autoridad, el Órgano de solución de diferencias, lo que le permite aplicar las decisiones y los compromisos asumidos por los países dentro de ella.
}

como un posible eje programático de la Unesco: "La creatividad cultural es la fuente del progreso humano y la diversidad cultural, siendo un tesoro de la humanidad, es un factor indispensable de desarrollo", en este sentido "una de las funciones de las políticas culturales es de proporcionar el espacio necesario para el florecimiento de las capacidades creativas"15. Más allá de la simple constatación conceptual, este evento marca el nacimiento de un conjunto de acciones que van a ir forjando el principio de diversidad cultural, tal como se encuentra en la Convención de 2005.

Además de la Unesco, numerosos gobiernos, organizaciones e instituciones del sector público como privado, respondieron afirmativamente de forma individual y colectiva al contenido del "plan de acción". Esta nueva toma de conciencia dio lugar a diversas iniciativas, como la canadiense. De hecho, su gobierno se constituirá en uno de los principales movilizadores del discurso de la diversidad cultural, tanto a nivel gubernamental como a través de las iniciativas desarrolladas por el mundo asociativo. Por una parte, Canadá se impregna del movimiento que estaba ya en marcha en la Unesco para tomar iniciativas por su cuenta, coadyuvando el hecho de que quien se encontraba en ese momento a la cabeza del Ministerio del Patrimonio era un personaje como Sheila Copps. Con amplia experiencia en el campo de las comunicaciones y una pujante trayectoria política, organiza una reunión que congregó más de 40 ministros y secretarios de Estado encargados de la cultura16 "para discutir formas de preservar las culturas locales y nacionales en un contexto de globalización y de una creciente homogeneidad"17.

Por su parte, el mundo cultural no estatal canadiense, inspirándose en las acciones emprendidas por sus pares franceses, comienzan a organizarse igualmente a partir de 1999, en oposición al AMI. Sobre el principio que "las políticas culturales no deben ser sometidas a las obligaciones de los acuerdos comerciales internacionales", se movilizan enérgicamente y fundan al poco tiempo la Coalición canadiense por la diversidad cultural, primera en su tipo. La ministra Copps va a establecer una estrecha relación con el sector de las colectividades profesionales de la cultura de su país. Consciente del lugar secundario que en términos concretos ocupa esta cartera de gobierno en todo Estado, ella comprende rápidamente la fuerza que el debate en torno a la diversidad cultural podía imprimirle a su gestión.

\footnotetext{
${ }^{15}$ Plan de Acción sobre Políticas para el Desarrollo, adoptado en Estocolmo el 2 de abril.

16 Los participantes reunidos en Ottawa (1998) acordaron establecer una red internacional informal para promover este objetivo, lo que más tarde se convertiría en la Red Internacional de Políticas Culturales (RIPC). Volviéndose a reunir en la Ciudad de México (1999), Grecia (2000), Suiza (2001), Sudáfrica (2002), Croacia (2003), China (2004), Dakar (2005), Brasil (2006), España (2007).

17 Rapport final de la Rencontre internationale sur la politique culturelle. La culture sur la scène mondiale. Ottawa, 1998.
} 
"Al inicio del movimiento en favor de la Declaración y luego, de un verdadero instrumento internacional para proteger la diversidad cultural, el responsable político canadiense, la Ministra [...] Sheila Copps, comprendió la gran importancia de buscar apoyo en la opinión pública y en los movimientos de la sociedad civil, que son esencialmente las asociaciones profesionales, para poder por su parte tener más peso, peso político, ante sus colegas, los otros miembros del gobierno" (Entrevista con Charles Vallerand) ${ }^{18}$.

En la misma línea de "visibilización" internacional y con una lectura estratégica, Copps compromete su respaldo a la Coalición, apoyándoles en la realización del Primer encuentro de asociaciones profesionales del ámbito de la cultura, celebrado en Montreal entre el 11 y el 13 de septiembre de 2001, el cual se reveló como el espacio desde el cual éstas últimas construirán su plataforma internacional. Bajo el título Diversidad cultural, Políticas culturales y Acuerdos internacionales de comercio, que anunciaba los tres grandes ejes que pondrían en tensión el debate, este encuentro posee un carácter embrionario en la articulación de una red asociativa multisectorial de los profesionales de la cultura a nivel mundial. Contando con la participación de 60 organizaciones venidas de doce países, va a constituir un antecedente fundamental, en su estructuración, para dar forma a un respaldo contundente a la generación de un instrumento jurídico internacional a favor de la diversidad cultural.

Estas reuniones promovidas por Canadá, junto con comportar un espacio para pensar la cultura, impulsaron acciones inclinadas a que "la Unesco desempeñe un papel activo en este proceso"19. En junio de 1999, y con el apoyo y la cooperación del Ministerio de Patrimonio Canadiense y la Comisión Nacional Francesa para la Unesco, se organizó un simposio que planteaba la interrogante: "La cultura: ¿una mercancía distinta de las demás?". Reuniendo a artistas, profesionales, abogados, economistas y otros expertos en los sectores de cultura y audiovisual, públicos y privados, de todo el mundo, los debates se centraron en los aspectos económico y comercial de la cultura, tal como se destacaron en Estocolmo y se dejó en claro que la Unesco tenía un papel sustancial que jugar para "promover el debate internacional sobre las estrategias adecuadas para aplicar en las negociaciones internacionales y en el contenido y en los métodos de la acción gubernamental, así como en el debate sectorial sobre la situación de las industrias culturales en las diferentes regiones" 20 .

\footnotetext{
${ }^{18}$ Entrevista con Charles Vallerand, Presidente de la Federación Internacional de Coaliciones por la diversidad cultural. París, 2010.

19 Rapport final de la Rencontre internationale sur la politique culturelle, op. cit.

20 UNESCO. 1999. "La culture : une marchandise pas comme les autres ? », Colloques d'experts sur la culture, le marché et la mondialisation, Paris, Document final, p. 3.
}

Si la noción de diversidad cultural se levanta como estandarte de la Unesco, es porque se encontró con una dinámica interna favorable en su Secretaría ${ }^{21}$ y la voluntad de ciertos Estados miembros que, sumados a la profunda convicción de profesionales de la cultura en vías de transnacionalización, llevaron a este conjunto de actores a consolidarse como una tribuna para la defensa de la causa de la diversidad cultural. La eficacia simbólica del principio de diversidad cultural -y de las diferentes formas de argumentación o retórica- se articula en la relación compleja de las propiedades del discurso, de los individuos que lo enuncian y de la institución que autoriza a pronunciarlo (Bourdieu 1999: 71). De ahí que el proceso de elaboración y legitimación del principio de diversidad cultural va a ser el resultado de la movilización de grupos heterogéneos (políticos, artistas, científicos, profesionales de la cultura, etc.) que supieron poner en funcionamiento distintos tipos de recursos discursivos, asociados a los variados capitales simbólicos acumulados en sus campos de origen respectivos (cultural, político, asociativo, etc.).

Las propiedades sociales de los individuos que se implican en la defensa de la diversidad cultural, empiezan a configurar una forma de capital simbólico transnacional, que circulará en un espacio a diferentes escalas (actores locales, Estados, organizaciones internacionales), pues desbordan las fronteras nacionales. Fondo supranacional, el capital simbólico transnacional funciona como una instancia simbólica que acredita, sustenta, reconoce y legitima las acciones individuales o colectivas de sus adherentes. Las acciones emprendidas por estos últimos, les abren también oportunidades para producir efectos políticos, relativamente duraderos, en la medida en que les permite la formación de alianzas basadas en una ideología o interés con miembros del mundo político. Alianzas con capacidad de interrumpir, en cierta medida, la rutina de los procesos políticos, permitiendo que otros actores políticos externos al gobierno, también puedan ejercer presión sobre sus autoridades. Es efectivamente cuando existen instituciones democráticas estables y una abierta competición política, cuando las estrategias y las reivindicaciones de los movimientos sociales tienen más probabilidades de ser acogidas eficazmente (Tilly et al. 1998).

\section{La internacionalización como estrategia colectiva de resistencia: los Editores independientes chilenos}

Antes de entrar en los detalles de la creación de la Coalición chilena por la diversidad cultural, gestada a partir del Encuentro de Montreal, se torna necesario restituir la trayectoria de uno de sus miembros fundadores más activos. Hablamos del sector de la edición independiente,

\footnotetext{
21 La Secretaría de la Unesco no tiene legitimidad diplomática propia, pues su accionar responde al mandato de los Estados miembros. Sin embargo, por su modo de funcionamiento, para que las iniciativas de los Estados prosperen dentro de la organización, se requiere de una correspondencia de intereses entre éstos y la Secretaría.
} 
que comienza a organizarse a fines de los años noventa, en un escenario político y social marcado por la transición a la democracia. Estos editores, se han destacado por desarrollar un trabajo en redes a distinta escala y por los modos de acción desplegados en el espacio público, produciendo reordenamientos sobre la escena cultural y política nacional.

La emergencia de la edición independiente en Chile se aloja dentro de un proceso de recomposición del espacio editorial internacional a partir de los años 80. Este fenómeno, fraguado a partir de la caída del muro de Berlín y de una nueva escena política de extendida recuperación de la democracia en España, Grecia, Europa del este y los países de América latina, fue acompañada por una aceleración y multiplicación de los intercambios comerciales, aunque sin transformar significativamente la manera asimétrica en que circulan los productos culturales. En el mercado del libro, aparece una tendencia de fuerte concentración de sellos editoriales, que ha coexistido con el surgimiento permanente de proyectos editoriales alternativos.

En este nuevo paisaje de globalización editorial (Sapiro 2009), los editores independientes chilenos elaboran catálogos diferentes de los grandes grupos editoriales y se constituyen como un nuevo polo de producción. Si bien se trata de una participación que pone de relieve la acción colectiva, el papel jugado por el editor Paulo Slachevsky ${ }^{22}$ constituye un factor clave para comprender los itinerarios seguidos por este sector. En más de una veintena de entrevistas, realizadas con diversos editores y personalidades del mundo cultural, ninguno de los entrevistados dejó de subrayar las capacidades integradoras que posee Slachevsky y la incidencia que

\footnotetext{
22 Paulo Slachevsky, periodista, 48 años, creció en el seno de una familia que vive el exilio en Francia, país al que deben partir por la persecución a su tío, Jacques Chonchol, ministro de Agricultura del gobierno del presidente Salvador Allende. Slachevsky mantiene a pesar de esto, un contacto fluido con su país. A mediados de los años ochenta, comienza a trabajar como fotógrafo freelance, cubriendo las protestas de los últimos años del régimen de Augusto Pinochet y sumándose a la Asociación de fotógrafos independientes, AFI. En ese contexto es que conoce a quien será su esposa, la historiadora Silvia Aguilera, quien venía desarrollando un trabajo en el mundo de las asociaciones de derechos humanos, y de la lucha contra la dictadura. De esta manera Slachevsky comienza a impregnarse del país que había dejado a los once años y precisamente al momento de terminar su Bachillerato y de inscribirse en un programa de Filosofía y Economía en la Universidad de Nanterre, decide volver definitivamente a Chile. En 1990, fundan Lom, una pequeña editorial familiar, que se ha destacado por la riqueza y diversidad de su catálogo (ciencias sociales, narrativa, poesía, ensayos y fotografía), siendo actualmente una de las más consolidadas dentro de las independientes chilenas. El año 1997 publican "Chile actual: anatomía de un mito" de Tomás Moulian, que llega a posicionarse como una suerte de bestseller de la transición. Fue miembro fundador de la Asociación de Editores Independientes de Chile y la presidió entre 2000 y 2004 e igualmente de la Coalición chilena por la diversidad cultural, que preside por dos periodos. Slachevsky se ha destacado como una figura clave en el reposicionamiento del debate público sobre el Libro y la lectura en Chile. El año 2005 recibe la medalla de Oficial de las Artes y las Letras, distinción concedida por el Ministerio de Cultura francés.
}

tuvo en la manera en que se estructuró el mundo de los editores independientes en Chile.

El primer referente que surge de este contexto es Editores Independientes ${ }^{23}$, creada en 1998. Un colectivo regional compuesto por cuatro editoriales relativamente similares en cuanto a su tamaño y proyecto editorial, que coincidiendo en diversos encuentros y foros, empiezan a proyectar un espacio común desde donde articular un trabajo en conjunto: Lom (Chile), Era (México), Trilce (Uruguay) y Txalaparta (País Vasco, España). Al poco tiempo la idea es replicada a nivel local, la mayor parte de las pequeñas y medianas editoriales chilenas se agrupan en la asociación de Editores independientes de Chile ${ }^{24}$. Creada a fines de los 90, esta plataforma asociativa comienza a desarrollar respuestas al panorama de fuerte concentración editorial, y a la ausencia de políticas para el Libro y la lectura presente en Chile. Su programa ${ }^{25}$ se elabora subrayando la necesidad de contar con políticas culturales que aborden la situación del Libro y de su industria nacional, capaces de corregir la asimetría que ellos percibían en los intercambios culturales. ${ }^{26}$

Para explicar el contexto en que emerge este sector, la teoría de los campos, elaborada por Pierre Bourdieu, y de la cual ha habido numerosas aplicaciones al mundo de la edición, del cine, y de la traducción, entre otras (Bourdieu 1977; 1999; Sapiro 2010; Duval 2006), propone un esquema de análisis que nos resulta pertinente. Consiste en un modelo organizado en la oposición de dos polos: un polo de gran producción y otro de producción restringida. En el primero van a regir principalmente criterios comerciales, mientras que en el segundo imperan razones intelectuales, estéticas y/o identitarias. Las editoriales que componen Editores de Chile, pertenecen a este último, en él se exhibe un valor asociado a la pluralidad y la naturaleza de las obras producidas ${ }^{27}$ que,

\footnotetext{
${ }^{23}$ Estos editores se empiezan a encontrar paulatinamente en distintos espacios, como la feria de Frankfurt en 1996 y el Salón iberoamericano del libro de Gijón en 1998. Esta última fue la instancia clave que da origen a su colectivo. Así comienzan a darse cuenta que comparten algunas características de tamaño, estructura de negocio, funcionamiento, visión acerca del libro y proyecto editorial, y una experiencia similar, caracterizada por el lugar que ocupan en el espacio internacional de la edición. Esto les impulsó al desarrollo de procesos y prácticas de colaboración como la coedición de sus obras (70 títulos a la fecha).

24 Fundada por siete editoriales: Lom, Cesoc, Cuarto Propio, Cuatro Vientos, Dolmen, Pehuén y Ril, la asociación obtiene su personalidad jurídica en el año 2002, momento en que se incorporan las editoriales Aún creemos en los sueños y Dolmen. En 2003 el grupo adopta el nombre de "Editores de Chile, Asociación de Editores independientes, Universitarios y Autónomos". Actualmente cuenta con cerca de 50 miembros.

${ }^{25}$ Esto corresponde a un conjunto de diagnósticos y propuestas centrados fundamentalmente en: el precio fijo, un IVA diferenciado de un $7 \%$ para el libro (en Chile corresponde a un 19\%), el fortalecimiento de una red de bibliotecas públicas, la bibliodiversidad, la necesidad de intercambios equilibrados, entre otras.

${ }^{26}$ Sobre las asimetrías de los intercambios véase: Heilbron 2001; Sapiro 2008, 2009, 2010; Sapiro y Bustamante 2009.

27 Autores desconocidos u olvidados, géneros poco comerciales
} 
en su gran mayoría, no se publicarían dado su bajo interés comercial para el polo de la gran producción. Este último se encuentra representado en Chile por la Cámara Chilena del Libro $^{28}$. Cada polo de actores justifica su existencia y su posición a partir de la propia posición ocupada en el campo editorial, que no es estática ni permanente.

Los modos organizativos desplegados por Editores de Chile (EDIN) irán consolidándose hasta llegar a ampliarse hacia un circuito internacional, con su incorporación el año 2001, a la Alianza internacional de Editores Independientes ${ }^{29}$. Si bien, es claro que el cuadro regulatorio del ámbito cultural es específico para cada país, el trabajo en redes les provee de un repertorio de herramientas comunes, que van desde: cifras, diagnósticos, líneas programáticas de trabajo, materiales jurídicos, propuestas legislativas, hasta llegar a construir un lenguaje y un aparato conceptual compartido.

La participación progresiva en variados encuentros, ${ }^{30}$ instancias de intercambios con otros editores de distintos países, hace posible la fabricación sucesiva de elementos para pensarse desde una visión multifocal: tanto desde el propio lugar que detentan en el espacio cultural nacional, como de la posición que la edición independiente ocupa a nivel mundial. Sin duda, la toma de contacto con figuras emblemáticas de la edición independiente como el editor franco americano André Schiffrin, será clave para la constitución de un verdadero movimiento de la edición independiente.

Sobre la escena nacional, se trata de actores complejos que exhiben una doble posición: secundaria, en cuanto a su peso económico y financiero, pero a su vez, paradojalmente, determinante sobre el plano simbólico. Esta condición dual les lleva a asumir una estrategia colectiva que genera ciertos reordenamientos en el espacio editorial chileno: garantizan la producción de un catálogo heterogéneo, en término de los géneros y

(como la poesía), investigaciones sociales y sujetos especializados.

28 Creada en 1950, la Cámara chilena del Libro es una asociación gremial que reúne un centenar de miembros: empresarios de la edición, distribuidores, librerías y organizaciones de venta directa. La Cámara goza de un prestigio ligado a su antigüedad y tradición, que hacen de ella una institución reconocida. Por otra parte, este prestigio se explica por las relaciones que cultiva con los grandes grupos editoriales transnacionales con sede en el país, que forman parte de ella. Entre estos el Grupo Planeta, Fondo de Cultura Económica, Grupo Santillana, Random House Mondadori y Mc Graw Hill. La Cámara se destaca además por organizar la Feria del libro de Santiago, el mayor evento en su género del país y por su trabajo en la promoción de instrumentos de persecución de la piratería.

29 La Alliance International des éditeurs indépendants constituye el referente mundial del mundo editorial independiente. Creada en Paris, en 2001, está estructurada por áreas lingüísticas.

30 Desde el Primer encuentro de Editores independientes de América Latina (Gijón, 2000), el Encuentro de Dakar (2003), el Seminario Los editores independientes del mundo latino y la Bibliodiversidad (Guadalajara, 2005), el Congreso del Grupo Interamericano de Editores (Madrid, 2006), el Seminario internacional Hacia una política de integración del Libro latinoamericano (Santiago, 2007), entre otros. temáticas abordados, y cumplen una función revitalizante respecto a la instalación de la problemática del libro y la lectura en Chile, empujando constantemente el diálogo entre el campo político y el cultural. Es en la constitución y acumulación de un cierto capital simbólico, que se fue forjando un actor que en los últimos veinte años se ha convertido en indispensable para comprender la manera en que circula y se integran localmente categorías como diversidad cultural y bibliodiversidad en el paisaje cultural chileno.

\section{De circuitos nacionales a redes transnacionales: la Coalición chilena por la diversidad cultural}

Las recientes investigaciones sobre las acciones colectivas transnacionales, se han esforzado en teorizar estos movimientos aislando las estrategias internacionales de su contexto nacional. Esto es, inscribiéndolas en categorías con pretensiones universales, "existe la tentación de descontextualizar las estrategias internacionales al explicarlas de acuerdo con categorías como 'las comunidades epistémicas'o 'las redes multilaterales de promoción de causas sociales', las cuales destacan únicamente el carácter internacional de los actores involucrados"(Dezalay y Garth 2002: 32), describiendo de manera tan idealista como normativa la emergencia de una "sociedad civil internacional". Los autores plantean que "con frecuencia, la terminología no es la misma, incluso cuando las palabras son expresadas en el mismo idioma, y aquellas que tienen el mismo nombre pueden llegar a denotar diferentes estratos sociales" (Dezalay y Garth 2002: 32), es decir, que estos enfoques se limitan a subrayar el carácter internacional de los agentes, descuidando los recursos y las decisiones estratégicas que deben a las posiciones que ocupan en sus campos nacionales. Por esta razón, nos hemos concentrado en restituir las trayectorias de los agentes implicados y los contextos nacionales sobre las cuales derivan sus prácticas en Chile y en la manera como estas prácticas dan sentido a sus acciones concretas.

El mundo de la edición independiente chilena venía desarrollando, como ha sido descrito, un trabajo asociativo consistente en el tiempo, que empezaba a visibilizarse poco a poco. Esto explica en cierta medida el hecho que, cuando la Coalición canadiense inicia la toma de contacto con las asociaciones profesionales de la cultura chilenas, lo hiciera a través de los editores. El año anterior y en el marco de la visita de una delegación canadiense a Santiago, el editor de Editions du Boréal (Montreal) se acerca al presidente de la Asociación de Editores independientes, y es a quien vuelven a contactar para extender la invitación a los participantes del Encuentro de Montreal, realizado en 2001. Hasta ese momento, las asociaciones chilenas no tenían mayor vínculo entre sí, más allá del reconocerse como pertenecientes al mismo "medio cultural" nacional. El conocimiento acerca de lo que cada cual realizaba en su 
respectivo ámbito era mínimo y sus relaciones internas se caracterizaban por su atomización. De hecho, es la primera vez que éstas coinciden en una instancia. ${ }^{31}$

El eje temático de la reunión de Montreal giró en torno a la diversidad cultural, cuestión hasta ese momento prácticamente desconocida para las agrupaciones chilenas. Si bien ya estaba presente la idea de que el mercado no debería ser la dimensión determinante de su actividad, no portaban en su argumentación un trazado conceptual-jurídico como el que se desarrollaría posteriormente. La construcción de una visión sobre la necesidad de disponer de un estatuto diferencial para los bienes culturales, como su puesta en circulación, corresponde a un programa que sólo es posible pensar de manera global, dada la imbricación con que operan los mercados. En este sentido, el Encuentro jugó un papel relevante en la visualización de problemáticas comunes así como en el desarrollo de líneas de acción a proyectar colectivamente. Se trata de un debate que les hace sentido y les cambia la óptica respecto al grado en que esta temática les concernía directamente.

"[...] estuvimos cuatro representantes de Chile y ahí nos dimos cuenta, de verdad, de que evidentemente el trabajo que nosotros estábamos haciendo en Chile a nivel de las Asociaciones profesionales de la cultura era como una cosa muy metida para adentro, muy como la avestruz, que estábamos mirándonos a nosotros mismos nomás, no veíamos lo que pasaba en el mundo. Y entonces nos empezamos a dar cuenta de que habían un montón de elementos a nivel internacional con relación a la cultura que nosotros no teníamos idea" (Entrevista con Mané Nett) $^{32}$

Nett sugiere que el Encuentro lleva a las asociaciones a ver hasta qué punto se encontraban volcados hacia la situación local y a reconocer su desvinculación de las problemáticas que sus pares se encontraban trabajando a nivel mundial.

Los aspectos cruciales de esta jornada serán: en primer lugar su carácter federativo, instituyente de un espacio de pertenencia simbólico: "la red internacional de

\footnotetext{
${ }^{31}$ Cuatro organizaciones conformaron la delegación chilena que asiste a Montreal: Sidarte, Sindicato de actores de Chile, representado por Mané Nett, Nano Acevedo, por el Sindicato Nacional de Trabajadores de la Música de Chile (SITMUCH), Bruno Betatti en representación de la Asociación de Productores de Cine y Televisión de Chile y por la Asociación de Editores independientes, Paulo Slachevsky, quien es invitado a hablar en la jornada inaugural, a nombre del mundo cultural chileno.

32 Entrevista con Mané Nett, julio 2009. Nett es actriz de teatro y televisión. Ha sido dirigente del Sindicato de actores por casi dos décadas. Actualmente está consagrada a un tercer período como presidenta de la Coalición chilena por la diversidad cultural y acaba de ser reelecta como representante del área Latinoamericana de la Red Internacional de Coaliciones.
}

Asociaciones Profesionales de la Cultura" (en adelante APC). El encuentro de Montreal se constituye para las asociaciones chilenas en una coordenada que va a cimentar el relato de su memoria institucional, más o menos compartida, que repercutirá en sus trayectorias individuales y colectivas. En segundo lugar, genera un espacio concreto de referencia, soporte de circulación de informaciones y un cúmulo de instrumentos en construcción (conceptos, manifiestos, cifras, herramientas jurídicas, etc.), los cuales movilizan en el ámbito local. En esta línea, Slachevsky rememora de qué forma el Encuentro les conduce a implicarse directamente en el debate sobre la diversidad cultural, determinando su "toma de consciencia y [mostrando] el camino para las asociaciones culturales chilenas frente a los tratados de libre comercio que estaban a punto de ser firmados [por Chile] con la Unión Europea y EEUU"33. Es decir, la jornada lejos de reducirse a un espacio testimonial, busca concertar acciones colectivas a fin de producir efectos concretos en el campo político nacional.

El estado del arte respecto a la relación cultura y comercio expuesto por los diferentes participantes, conduce a las asociaciones chilenas a constatar que la situación de la cultura en Chile, lejos de ser un caso específico, corresponde a una constante mundial. Esta lectura espacial, donde se imbrican relaciones de poder nacionales e internacionales, los lleva a elaborar una declaración inmediatamente a su regreso a Santiago. Bajo el título "A resguardar la libertad de acción del Estado chileno en el ámbito de la cultura", las ACP chilenas se posicionan en el propio escenario de negociaciones al que asistía Chile en ese momento, ad portas a la firma de un TLC con EEUU. La declaración, traduce los principales debates y preocupaciones a su contexto nacional. Es una operación que informa al gobierno de la participación que han tenido en una suerte de cónclave asociativo mundial de APC y le llama a hacerse parte del debate, en tanto Estado chileno:

"Reunidos en Montreal [...] debatimos sobre la cultura en el marco de la globalización y el necesario resguardo de la diversidad cultural [...]. Estamos convencidos que la creación artística con toda su diversidad y complejidad no puede estar regida sólo por la lógica del mercado, pues esa tiende a generar procesos de concentración y uniformización de la producción que limitan la posibilidad de circulación de productos locales y de géneros no comerciales. Por ello es fundamental el rol del Estado como garante de esa necesaria diversidad. [...] Cuando se avanza con paso firme en el establecimiento del TLC con EEUU, se hace más necesario que nunca hacer

\footnotetext{
33 "Des paroles et des actes pour la bibliodiversité". Paris, Alliance des éditeurs indépendants, p.57. Encuentro "Los editores independientes del mundo latino y la bibliodiversidad", 27- 30 noviembre de 2005. Guadalajara, México.
} 


\begin{tabular}{|c|c|c|c|}
\hline \multirow{2}{*}{$\begin{array}{c}\text { Escala de análisis } \\
\text { Supranacional }\end{array}$} & \multirow{2}{*}{$\begin{array}{c}\text { Espacios de homología de } \\
\text { posiciones }\end{array}$} & \multicolumn{2}{|c|}{ Oposiciones en los espacios } \\
\hline & & UNESCO & OMC, OCDE \\
\hline Internacional & Entre Estados & Francia, Canadá, Chile & EEUU \\
\hline Transnacional & $\begin{array}{l}\text { Entre redes internacionales de } \\
\text { grupos de interés }\end{array}$ & Coaliciones DC & $\begin{array}{c}\text { Empresas multinacionales (ej. } \\
\text { Motion Pictures Association of } \\
\text { America (MPAA) }\end{array}$ \\
\hline Nacional & $\begin{array}{l}\text { Entre polos de producción } \\
\text { (sector editorial en Chile) }\end{array}$ & $\begin{array}{l}\text { Asociación de Editores Inde- } \\
\text { pendientes }\end{array}$ & Cámara chilena del libro \\
\hline
\end{tabular}

Tabla 1. Espacios de homologías de posiciones entre agentes (o instituciones)

Table 1. Position homologies spaces between agents (or institutions)

valer el derecho y deber del Estado chileno de resguardar la capacidad de definir sus propias políticas culturales [...], creemos que poco serviría tomar medidas o dictar leyes a favor del desarrollo cultural, si por otro lado se firman acuerdos que por omisión han de limitar toda aplicación concreta de políticas de fomento a la producción el día de mañana".

Un par de semanas después, en octubre de 2001, se constituyen como Coalición chilena por la diversidad cultural (CDC), será la segunda después de la canadiense. Eligen un directorio, del cual resultan electos Paulo Slachevsky como presidente y Mané Nett vicepresidenta. La CDC comienza a trabajar en seguida en la preparación de un programa, y a movilizarse planteando la necesidad de obtener una reserva cultural en el TLC con EEUU, postura argumentada a través de diversos documentos.

Como podemos observar, si bien los participantes chilenos se identifican rápidamente con la lucha contra la "globalización mercantil de la cultura", la mayoría de sus iniciativas estaban también profundamente arraigadas en formas nacionales de activismo, desarrollado en un contexto particular de la política local. En este sentido, según Tarrow el activismo transnacional no surge como una simple respuesta a la globalización, pues los agentes identifican problemas y formulan demandas, movilizan los recursos necesarios y aprovechan las oportunidades en los espacios políticos a diferentes niveles, como por ejemplo la creación de coaliciones transfronterizas. Los procesos de activismo transnacional vinculan eficazmente las cuestiones mundiales con los problemas nacionales. La internacionalización de la contestación contribuye a establecer una difusión transnacional de estrategias y tácticas, que tienden a proyectarse hacia arriba para hacer frente a las instituciones internacionales y nacionales o viceversa (Tarrow 2005). Por otra parte, a pesar de que las instituciones internacionales siguen reflejando el poder del Estado nacional, ofrecen igualmente nuevos espacios para el activismo transnacional, como lo hemos evocado en las iniciativas emprendidas al interior de la Unesco.

\section{Las reivindicaciones políticas del campo cultural}

La creación de la Coalición chilena por la diversidad cultural se inscribe en un movimiento más amplio que se activó a partir del Encuentro de Montreal, punto de partida de la concepción y propagación del modelo de coaliciones $^{34}$. Desde ahí, el mundo cultural asociativo, comienza a demandar a sus gobiernos una participación más enérgica en el resguardo de la cultura como un asunto de interés público y nacional. Es así como, la aparición de la cuestión de la diversidad cultural en la agenda política chilena, fue posible gracias a un momento de convergencia entre dos dimensiones de la acción política, la nacional e internacional. Este puede explicarse a la luz del concepto de homología estructural entre dos espacios, que Dezalay y Garth, utilizan para analizar las estrategias presentes en las importaciones/ exportaciones de experticia entre campos nacionales diferentes. Los autores postulan que dependiendo del grado de homología estructural que pueda existir entre distintos campos de Estado, en un momento específico de su historia, se consolida la alianza - siempre precaria entre importadores y exportadores de un saber experto (Dezalay y Garth 2002).

Para el caso que hemos presentado en nuestro artículo, no se trata solo de intercambios entre grupos de poder dentro de los Estados sino, y sobre todo, de una forma de homología estructural de posiciones entre grupos pertenecientes a espacios transnacionales complejos que interactúan a distintas escalas (organizaciones internacionales, Estados, redes internacionales de profesionales de la cultura $(A P C)$, sectores culturales nacionales). Sus puntos de convergencia son evidentemente la defensa de postulados que ellos consideran como legítimos. Sin embargo, defendiendo sus visiones del mundo, revalorizan también

\footnotetext{
34 El cual derivó en la creación, en 2007 - en el Congreso constituyente de Sevilla- de la Federación Internacional de Coaliciones para la Diversidad cultural (FICDC). Esta federación cuenta con 42 coaliciones nacionales y comprende más que 600 organizaciones de profesionales de la cultura.
} 
las posiciones que ocupan en sus campos de pertenencia, gracias a la acumulación de un tipo de capital simbólico trasnacional, tan duradero como vigente sea la causa que se defiende en el espacio transnacional (ver Tabla 1).

El principio de diversidad cultural, engendrado en una organización internacional, respaldado en sus inicios por ciertos países (particularmente Canadá y Francia), difundido por coaliciones internacionales de profesionales de la cultura, reivindicado de manera local por asociaciones nacionales, regresará a la organización que lo concibió recubierto de un capital simbólico constituido por su recorrido y reconocimiento transnacional.

Para el caso chileno, con un escenario de fuerte apertura económica ${ }^{35}$ emprendida durante los gobiernos democráticos, el ingreso de la cuestión de la diversidad cultural en la agenda política se hace posible al coincidir con la última ronda de negociaciones del TLC con EEUU. Este contexto de negociaciones ya bastante avanzadas, se presenta como una ventana de oportunidad sin precedentes para la Coalición por tratarse de un espacio que se encontraba operando y contaba con determinados plazos de aprobación. Los representantes de la Coalición plantearán la necesidad de un tratamiento particular para la cultura. Es en la movilización de este discurso que las asociaciones profesionales de la cultura van a construir el suyo, desplazándose permanentemente entre el campo cultural y el político hasta llegar a crear una intersección entre ambos, constituyéndose en una suerte de mediadores permanentes. Estos actores se autoconciben como portadores de una dimensión pública, en cuanto representantes de la sociedad civil del ámbito de la cultura ${ }^{36}$. Toman la palabra pública para hablar en nombre del desarrollo del país y del fortalecimiento de la cultura ciudadana, advirtiendo sobre los riesgos que comportaría para la creación y la Educación firmar un TLC sin exclusiones. Su accionar se traduce concretamente en tres tiempos:

Un primer momento, en que se esfuerzan por apropiarse de un discurso experto. Un segundo, en que desarrollan estrategias de visibilización de la problemática, a través de la multiplicación de intercambios con los diversos actores involucrados en el debate. Así se van entrenando poco a poco en la constitución de un cierto esquema de participación comprometida, fundado sobre las lógicas del campo cultural. Y un último momento, en que esta visibilización obliga a los poderes públicos a posicionarse frente al tema.

Mané Nett, relata las dificultades que encontraron para llevar a cabo un debate con los responsables técnicos de la negociación. Efectivamente, la gestión pública

\footnotetext{
${ }^{35}$ Hasta la fecha Chile ha firmado 21 Acuerdos comerciales con 58 países. Fuente: www.direcon.gob.cl

36 La Coalición chilena por la Diversidad Cultural es recibida en las instancias gubernamentales como representante de la sociedad civil.
}

como cada terreno posee su propio lenguaje técnico y lógicas de funcionamiento especificas $-y$ una visión de la negociación más o menos interiorizada- es el tecnócrata que dialoga con otros actores que tienen también sus propias maneras de concebir los temas: "Nos preguntaban por cifras y nosotros, las asociaciones profesional de la cultura, con relación a las cifras: ¡ninguna idea! nosotros argumentamos de otra manera" (Entrevista con Mané Nett). Es así como comienzan a actuar en varias direcciones: contactan a senadores y diputados, a personalidades y responsables políticos del ámbito cultural, presentan documentos y elaboran una Declaración pública; construyen una forma argumentativa técnica para debatir en el campo político, cuyo eje de acción y horizonte, estuvo marcado por la firma de la Convención. Invitan a Robert Pilon, vicepresidente de la Coalición canadiense y envían una "Carta abierta al Presidente Ricardo Lagos"37 (2002), quien les recibe en el Palacio de la Moneda ${ }^{38}$ para conversar sobre el tema.

Un factor, que consideramos pertinente mencionar en la entrada del debate sobre la diversidad cultural a la agenda pública chilena, es cómo operó la imagen de "presidente con una profunda sensibilidad frente al mundo de la cultura" que Ricardo Lagos, el mandatario de la época, había madurado a través de una relación de cercanía ${ }^{39}$ con los intelectuales y artistas. Esta imagen queda de manifiesto en un pasaje de entrevista con Nett: "el Presidente Lagos entendió el proceso en forma inmediata, [...] de alguna manera fue el impulsor para que evidentemente lo que nosotros estábamos planteando, llegara a oídos de donde tendría que haber llegado más allá de él [...]". Esta sensación de receptividad que generase Ricardo Lagos, más allá de si hubo o no avances efectivos en el ámbito de las políticas culturales durante su mandato, le permite consolidar lazos con el mundo de la cultura y el arte. Paulo Slachevsky, en su discurso ante la Unesco en 2003, le cita de manera estratégica, comprometiéndolo en el debate y poniendo en relieve el lugar que el desarrollo de la cultura debiera ocupar para evitar "ser meros receptores pasivos de objetos y valores culturales que se producen en otras latitudes", advirtiendo sobre los puntos negativos a que conlleva una globalización que se reduzca a la sola dimensión mercantil ${ }^{40}$. Afirmándose en esta visión, los representantes

\footnotetext{
${ }^{37}$ Este documento fue firmado por cerca de 500 representantes del sector de la cultura, con su nombre y la actividad que realizan. Entre ellos encontramos a las artes visuales, escultores, realizadores, pintores, escritores, académicos, arqueólogos, traductores, periodistas, etc. 38 Designada comúnmente como La Moneda, es la sede de gobierno de la República de Chile.

39 Durante su mandato, Ricardo Lagos nombró un asesor cultural presidencial, el actual premio Nacional de Ciencias sociales Agustín Squella. Su gestión estuvo marcada por varios hitos como: la realización de una temporada de conciertos en La Moneda, su reapertura para ser visitado por la ciudadanía; un ciclo de "conferencias presidenciales" dictadas por destacadas figuras académicas del mundo entero, la construcción de la Biblioteca de Santiago, entre otros.

40 Discurso de Paulo Slachevsky. Unesco, 2003.
} 
de la CDC establecen dos objetivos orientadores de su accionar. Por una parte, el lograr la incorporación de una reserva en el TLC con EEUU, y por otra, la interpelación al Estado chileno para la aprobación de la Convención sobre la diversidad cultural de la Unesco. A partir del esbozo de estos lineamientos, inician conversaciones con responsables y negociadores de Direcon. ${ }^{41}$

Chile y Canadá habían ya negociado un TLC en 1995, el cual entra en vigencia a partir de 1997. En el marco de estas negociaciones, fue precisamente Canadá quien incorporó el principio de excepción cultural, definiendo un ámbito muy amplio de aplicabilidad ${ }^{42}$. De hecho, las industrias culturales quedaron totalmente excluidas del tratado. Esto nos permite comprender los problemas que estas últimas encontrarían frente a la aprobación de nuevos Tratados de libre comercio que los países socios firmaran con EEUU, quien no estaba interesado en la incorporación de excepciones en el campo de los bienes culturales.

"[...] la industria del cine de EEUU inició intensas gestiones ante la Embajada chilena, en Washington, para impedir que Chile hiciera alguna acción de este tipo. Estas acciones incluyeron una visita de Jack Valenti, presidente de la American Motion Pictures [sic], al Embajador Bianchi, para expresarle que si Chile mantenía su actitud [...], él intervendría personalmente ante el Senado de EEUU para impedir la aprobación del TLC [...]" (Entrevista con funcionario de la Direcon) ${ }^{43}$.

Si bien estas gestiones finalmente no prosperaron, se observa en el proceso la manera en que son asumidas las negociaciones y muestra lo que estaba en juego para la industria audiovisual norteamericana y para el amplio ámbito cultural chileno. Precisamente en ese mismo momento, el Congreso chileno se encontraba discutiendo un proyecto de "nueva institucionalidad cultural", que dio nacimiento al actual Consejo Nacional de la Cultura y las Artes (CNCA), versión heterodoxa de Ministerio de la Cultura (De Cea 2010), cuyos fondos concursables - de haberse firmado un tratado sin exclusiones - hubiesen podido ser adjudicados a cualquier proyecto artístico o cultural norteamericano. ${ }^{44}$

\footnotetext{
41 Dirección de Relaciones Económicas del Ministerio de Relaciones Exteriores de Chile.

42 En el anexo O "Excepciones" - 06 Industrias culturales, Quinta parte del TLC, éstas quedaron totalmente excluidas, salvo en lo que respecta a las rebajas arancelarias de algunos productos.

43 Entrevista con uno de los negociadores chilenos en el TLC. Santiago, julio de 2010.

${ }^{44}$ Esto explica en gran medida - a nuestro juicio - las razones por las cuales el mundo de la edición independiente concentrará sus esfuerzos con vistas a que se planteen exclusiones en el TLC, más que en la creación de la nueva institucionalidad cultural (CNCA). Los editores se avocan completamente a la firma de la Convención por parte del Estado, concibiendo que los grandes ejes de la cultura nacional se
}

La Coalición chilena se acerca a Direcon durante la negociación de este TLC, porque "sabía que EEUU tenía un interés ofensivo sobre el tema y (ella) prefería una excepción al estilo Canadá. Direcon tenía que balancear los intereses internos más ofensivos (de exportadores de servicios y bienes culturales) con los defensivos de la Coalición". ${ }^{45}$ La balanza de intereses, a la que alude esta declaración da cuenta finalmente de la tensión comercio/ cultura, constatación sobre la cual se erige todo el debate de la diversidad cultural y en la cual se sustenta la demanda de una revitalización de la acción de los Estados por parte de las asociaciones profesionales de la cultura. Finalmente se firma un TLC que claramente no incorpora todos los planteamientos de la Coalición, pero se logra una reserva cultural con EEUU, en la cual Chile se reserva el derecho de desarrollar políticas públicas en esta materia. A su vez, en el año 2005 el gobierno chileno será favorable para la creación, en el seno de la Unesco, de la Convención sobre la protección y la promoción de la diversidad de las expresiones culturales, que el Congreso ratificará dos años más tarde.

\section{Conclusiones}

La nueva batería de herramientas provista por Unesco, retraducida a la escena nacional, se transforma en una suerte de matriz conceptual mayor, a partir de la cual se incorporan los diversos diagnósticos y propuestas de uno de los polos de producción cultural en Chile. Se trata de un discurso que alude a una mayor participación del Estado en el ámbito de los bienes culturales, a través de la generación de políticas públicas y de medidas que apunten a su protección. En consecuencia, la apropiación de este discurso internacional se encuentra alojada dentro de un marco de oportunidad en el cual los actores no estatales, inscriben su accionar en una lógica de articulación transnacional, a fin de desarrollar estrategias de resistencia colectiva frente al proceso de globalización mercantil.

Las asociaciones profesionales de la cultura se van institucionalizando de manera permanente para defender una causa considerada como legítima. En este proceso irán constituyendo una suerte de capital simbólico transnacional, que es el resultado de una acumulación colectiva del prestigio que cada individuo aporta desde sus respectivos campos. Con el respaldo de este capital, el mundo cultural y asociativo chileno interpeló a su gobierno a asumir una posición respecto a la gestión de los bienes culturales, produciéndose un fenómeno de circulación internacional de ideas (y de formas de acción), que va desde lo supranacional a lo nacional, a través de

jugaban en ese escenario, como lo expresa Paulo Slachevsky: "se estaba avanzando en la política, con el ministerio de cultura, pero al mismo tiempo se estaban totalmente amarrando las manos con un TLC con EEUU, si no se hacía ninguna excepción". Entrevista con Paulo Slachevsky. Santiago, abril de 2009.

45 Entrevista con uno de los negociadores chilenos en el TLC. Santiago, julio de 2010. 
un circuito de asociaciones a nivel mundial. El Encuentro de Montreal les proporciona la posibilidad de impulsar en la arena local un debate emanado de una visión en vías de legitimación a nivel internacional. Sin embargo, la conformación de este espacio transnacional no implica en lo absoluto la pérdida de preeminencia del Estado en la toma de decisión final. Por el contrario, es éste la entidad central a partir de la cual se estructuran todas las formas de toma de decisiones; a nivel nacional, es al Estado y a los poderes políticos que lo representan, a quien se le atribuye la función de concebir o no la cultura como un sector pertinente de intervención pública. A pesar de ello, el espacio de acción transnacional les abre oportunidades para poder agenciar mejor sur recursos simbólicos, revitalizando su posición a fin de influenciar el campo político nacional.

La diversidad cultural va a sintonizar con el diagnóstico, hasta este momento no unificado, que se planteaban sobre su situación las diferentes asociaciones profesionales de la cultura en Chile. Nuestro análisis arrojó que la incursión de un tal debate en este país permitió la visualización de este mundo asociativo hasta llegar a posicionarse como un actor central en la escena político-cultural nacional. Al mismo tiempo, es en el curso de este proceso que -aun sin pertenecer a él - las asociaciones organizadas en Coalición se constituirán como actores temporales del campo político, influyendo sobre la arista cultural de la agenda política chilena. La apropiación del principio de la Unesco sobre la diversidad cultural constituye para ellos una clave de legitimación, al mismo tiempo que reformula sus trayectorias individuales y colectivas. Estos debates van a proveerles de un marco de referencia común para abordar sus problemáticas como sector, el cual se sustenta a partir de la articulación progresiva de un movimiento internacional de coaliciones, que comienza a gestarse en Canadá.

En el plano internacional, esta movilización condujo a una reconfiguración de las competencias de la Unesco, organización que a su vez delega su autoridad, confiriéndola al discurso autorizado (Bourdieu 1999). En efecto, es en su interior donde va a generarse el poder enunciativo del concepto de diversidad cultural, así como las estrategias que marcaron su ámbito de acción. Esto coincide con un momento de reposicionamiento de la Unesco en el concierto de las instituciones internacionales (Bustamante 2012). Ahora bien, es necesario destacar que esta eficacia simbólica logra materializase porque se presenta como alternativa -por no decir oposición- a los argumentos desarrollados por otras instancias, en particular la OMC, donde estaba en curso de negociación la liberalización mercantil de los productos culturales.

La hipótesis de la homología estructural es particularmente eficaz para explorar los niveles de interacción que pueden crearse entre espacios diferentes. Si bien, los agentes no se perciben como pertenecientes a un mismo mundo (poseen dinámicas y estructuras de funcionamiento distintas), se buscan, se reconocen, interactúan con el fin de capitalizar colectivamente sus recursos para la defensa de su causa. El capital simbólico transnacional, forma de poder invisible pero presente, desconocidoen su forma de poder, les brinda intersecciones para dinamizar sus acciones. Efímero y eficaz, este capital se mantiene vigente mientras la causa sea pertinente en el espacio transnacional. Los discursos, las instituciones, los Estados, así como los capitales simbólicos individuales y colectivos de los miembros que defienden ciertos principios, se oponen en luchas de poder, el poder de definir y clasificar el mundo social.

Paris, 21 de Noviembre 2012

\section{Agradecimientos}

Queremos expresar nuestro agradecimiento a Claude Michel, Mané Nett, Paulo Slachevsky,Pablo Lazo, Charles Vallerand y a los muchos otros que por razones diferentes no están citados en el presente artículo, quienes amablemente nos permitieron entrevistarlos. Agradecemos de manera especial a Yves Dezalay, quien nos brindó algunas horas para discutir este texto, como también a César Bunster, Fruela Fernández, Daniel Grimaldi, Sophie Noël, Juan Enrique Serrano, Françoise Sierra y Gustavo Sorá por sus lecturas y acertados comentarios que nos ayudaron a mejorar versiones preliminares de este trabajo.

\section{Bibliografía}

Alliance des éditeurs indépendants. 2006. Des paroles et des actes pour la bibliodiversité. Paris.

Bourdieu, P. 1977. La production de la croyance: contribution à une économie des biens symboliques. Actes de la recherche en sciences sociales, n¹3: pp. 3-43

Bourdieu, P. 1999. ¿Qué significa hablar?: lenguaje y poder simbólico. Madrid, Ed. Akal.

Bourdieu, P. 1992. Les règles de I'art. Genèse et structure du champ littéraire. Paris, Seuil.

Bourdieu, P. 1997. Méditations pascaliennes. Paris, Seuil.

Bourdieu, P. 1999. "Une révolution conservatrice dans I'édition ». Actes de la recherche en sciences sociales, n 126-127, vol. 126.

Bourdieu, P., L. Wacquant. 1998. "Sur les ruses de la raison impérialiste ". Actes de la recherche en sciences sociales, $\mathrm{n}^{\circ}$ 121-122, vol. 121.

Bustamante, M. 2007. "L'adoption de la diversité culturelle. Analyse sociologique d'une stratégie de légitimation culturelle ». Tesis de master en sociología 
(dir. Gisèle Sapiro), EHESS, Paris.

Bustamante, M. 2012. "Winning Back an International Institutional Legitimacy. UNESCO and the conception of the notion of cultural diversity". European Studies Programme, University of Delhi, Working Paper Series XIV.

De Cea, M. 2010.L'Expérience chilienne du gouvernement de la culture: Vers une véritable politique culturelle. Tesis doctoral en Ciencia Política (dir. Guy Saez). Institut d'Études Politiques, Université de Grenoble, Francia.

Dezalay, Y., G. Bryant. 2002. La internacionalización de las luchas por el poder. La competencia entre abogados y economistas por transformar los Estados latinoamericanos. Santiago, ILSA/Universidad Bolivariana.

Dubois, V. 1999. La politique culturelle: genèse d'une intervention publique. Paris, Ed. Belin.

Duval, J. 2006. « L'art du réalisme. Le champ du cinéma français au début des années 2000 », Actes de la recherche en sciences sociales, $n^{\circ} 161-162$ : p. 96-115.

Gagné, G. 2005. La diversité culturelle: vers une convention internationale effective? Montréal, Ed. Fides, Collection Points Chauds.

Garretón, M. 1995. Hacia una nueva era política. Santiago, FCE.

Gournay, B. 2002. Exception culturelle et mondialisation. Paris, Presses de Science Po.

Heilbron, J. 2001. "Échanges culturels transnationaux et mondialisation: quelques réflexions ", Regards sociologiques, $\mathrm{n}^{\circ} 22$.

Joignant, A. 2009. «La politique des 'transitologues': Luttes politiques, enjeux théoriques et disputes intellectuelles au cours de la transition chilienne à la démocratie ». Politique et Sociétés, n²-3, vol. 24: pp. 33-59.

Mac Bride, S. 1988. Un solo mundo, voces múltiples: comunicación e información en nuestro tiempo. México, FCE.

Mattelart, A. 2005. Diversité culturelle et mondialisation. Paris, La Découverte.

Mattelart, T. 2011. La 'Diversité culturelle' : quelques éléments de déconstruction théoriques. In Bouquillion P., Y. Combès Diversité et industries culturelles. Paris, L'Harmattan.

McAdam, D. 1983. "Tactical Innovation and the Pace of Insurgency". American SociologicalReview, vol. 48, $\mathrm{n}^{\circ}$ 6: pp. 735-754.
Neveu, E. 2000. Sociología de los movimientos sociales. Quito, Ed. Abya Yala.

Noël, S. 2009. La petite Edition indépendante face à la globalisation du marché du livre : Le cas des éditeurs d'essais 'critiques'. In Sapiro (dir). Les contradictions de la globalisation éditorial. Paris, Nouveau Monde.

Noël, S. 2012. L'édition indépendante critique: engagements politiques et intellectuels. Villeurbanne, Presses de l'Enssib, collection Papiers.

Pérez de Cuéllar, J. (dir.). 1997. Nuestra Diversidad Creativa. Paris, Ed. Unesco.

Regourd, S. (dir.). 2004.De l'exception à la diversité culturelle. Paris, La Documentation française.

Sapiro, G.2004. « Le savant et le littéraire ». In Heilbron J. et al. Pour une histoire des sciences sociales. Paris, Fayard.

Sapiro, G. (dir.). 2007. « La traduction comme vecteur des échanges culturls internationaux: circulation des livres de littérature et de sciences sociales et évolution de la place de la France sur le marché mondial de l'édition de 1980 à 2002 ». Informe de investigación. Paris, Centre de sociologie européenne.

Sapiro, G. (dir.). 2008. Translatio: Le marché de la traduction en France à l'heure de la mondialisation. Paris, CNRS.

Sapiro, G. (dir.). 2009. Les contradictions de la globalisation éditoriale. Paris: Nouveau Monde.

Sapiro, G. 2010." Les échanges littéraires entre Paris et New York à l'ère de la globalisation ». Rapport de recherche, Centre européen de sociologie et de science politique.

Sapiro, G. y M. Bustamante. 2009. "Translation as a Measure of International Consecration. Mapping the World Distribution of Bourdieu's Books in Translation", Sociologica, $\mathrm{n}^{\circ} 2-3$.

Siméant, J. 2005. "Des mouvements nouveaux et globaux? Sur les mouvements sociaux « transnationaux "dans quelques ouvrages récents". Congreso de la Asociación francesa de ciencias políticas, Lyon, Mesa $\mathrm{n}^{\circ} 1$.

Symmes, C. 2009. "La dimension culturelle de la transition politique chilienne : Le cas de la maison d'éditions Lom ». Tesis de master en sociología (dir. Yves Dezalay), EHESS, Paris.

Tarrow, S. 2000. "La contestation transnationale ». Cultures \& Conflits, $\mathrm{n}^{\circ}$ 38-39. 
Tarrow, S. 2005. The New Transnational Activism.New York, Cambridge University Press.

Tilly, C. 1978. From Mobilization to Revolution. First Edition Stated, McGraw-Hill College.

Tilly, C., S. Tarrow y D. McAdam. 1998. " Pour une cartographie de la politique contestataire ». Politix, $\mathrm{n}^{\circ}$ 41, vol. 11, pp. 7-32.
Tilly, C., S. Tarrow y D. McAdam. 2001. Dynamics of Contention. Cambridge University Press.

UNESCO. 2005. Echanges internationaux d'une sélection de biens et services culturels 1994-2003 : Définir et évaluer le flux de commerce culturel mondial. Montréal, Secteur de la Culture de I'UNESCO, Institut de statistique. 